\title{
The social utility of performance-approach goals in a selective educational environment
}

\author{
Mickaël Jury ${ }^{1}$ (D) Céline Darnon ${ }^{1}$ • \\ Benoit Dompnier ${ }^{2} \cdot$ Fabrizio Butera ${ }^{2}$
}

Received: 25 March 2016/ Accepted: 3 August 2016/Published online: 29 December 2016

(C) Springer Science+Business Media Dordrecht 2016

\begin{abstract}
According to the recent research, the educational system fulfills both an educational function (i.e., teaching and training students) and a selection function (i.e., determining students' future position in the social hierarchy), particularly in higher education. It has been argued that in the university system the selection function provides a social utility value to performance-approach goals (i.e., the goal to demonstrate one's own competences relative to others), which in turn increases the extent to which students endorse these goals. Two experiments investigated the influence of the salience of the selection function on performance-approach goals' social value and endorsement. The results showed that the salience of the selection function increased both performance-approach goal endorsement (experiment 1 and 2) and performance-approach goals' social utility (experiment 2). These goals' social utility contributes to explaining the effect of the salience of the selection function on performance-approach goal endorsement. Limitations of the present experiments and practical implications are discussed.
\end{abstract}

Keywords Motivation - Achievement goals - Selection · Higher education · Social value

\section{Introduction}

Many scholars have pointed out that the University system is a highly competitive educational environment and that succeeding in such system often implies one's superior performance as compared with others (Alon 2009; Harackiewicz et al.

Mickaël Jury

mickael.jury@gmail.com

1 Laboratoire de Psychologie Sociale et Cognitive, Université Clermont Auvergne, 34 Avenue

Carnot, 63037 Clermont-Ferrand, Cedex, France

2 University of Lausanne, Lausanne, Switzerland 
1998). Among different achievement goals defined in the literature (Elliot 2005), the goals that focus on the desire to outperform others have been labelled "performance-approach goals" and have been differentiated from mastery-approach goals (i.e., focused on self-improvement or task mastery) and performanceavoidance goals (i.e., desire not to be outperformed by others). ${ }^{1}$ Research has demonstrated that endorsing this kind of goals is not neutral because performanceapproach goals are linked to both positive and negative outcomes (for a review, see Moller and Elliot 2006). Probably because of such mixed findings, a debate among researchers has long focused on whether performance-approach goals should or should not be promoted in classrooms (Brophy 2005; Harackiewicz et al. 2002; Kaplan and Middleton 2002; Senko et al. 2011).

Notwithstanding these theoretical debates, it appears that some empirical research has documented that even if the prevalence and strength of self-reported performance-approach goals is lower relative to other achievement goals (partly due to self-presentation concerns, see notably Sect. 1.3), some students indeed pursue performance-approach goals, particularly in high-performing schools (Pope 2001). This state of affairs may appear to be surprising to the extent that performanceapproach goals are perceived by most teachers and researchers as 'unfortunate and cynical approaches to academic life' (Nicholls 1989, p. 102) and thus are not officially promoted in classrooms. However, such paradox could be explained by the ambivalent role of the University system in modern Western societies. Indeed, as we will argue, the University system conveys quite an ambivalent image, presenting itself with an educational function while performing a selection function (Dornbusch et al. 1996). In the present research, we test the hypothesis that the selection function of University is responsible for students' endorsement of performance-approach goals at the University because it strengthens their perception of these goals as a useful means to reach success in this educational context.

\subsection{Antecedents of performance-approach goal endorsement}

What motivates students to endorse performance-approach goals? Researchers in the field of achievement goals agree that both individual and contextual reasons may be responsible. Regarding individual characteristics, research has found that perceived competence, competitiveness, or an entity lay-theory of intelligence are predictors of performance-approach goal endorsement (Cury et al. 2006; Murayama and Elliot 2012). Looking at contextual incentives, some authors argued that the school climate could contribute to students' motivation (Berger and Archer 2016; Maehr and Midgley 1991; Skaalvik and Skaalvik 2013, for a review see Wang and Degol 2015). Notably, several authors noted that classroom goal structures are important predictors of achievement goal endorsement (Ames 1992; Meece et al. 2006; Skaalvik and Federici 2016; Urdan and Schoenfelder 2006). More

\footnotetext{
1 Recent conceptualization of achievement goals (Elliot and McGregor 2001; see also Elliot et al. 2011) also includes mastery-avoidance goals. Nevertheless, as Elliot (2005) noted, these goals are presumed to be less prevalent compared to others, specifically in achievement contexts typically studied in the achievement goal literature. Moreover, they were not directly relevant to the question addressed in the present research. Therefore, these goals were not included in the present research.
} 
specifically, instructional practices that emphasize the correctness of the answer rather than the process of learning (Urdan and Schoenfelder 2006), teachercontrolled strategies (Nichols et al. 2003), norm-based assessment (Pekrun et al. 2014), and competition (Murayama and Elliot 2012) are examples of contextual factors that enhance students' performance-approach goals.

Despite the specificity of these contextual factors, some authors have noted that performance-approach goals can arise even in mastery-oriented classrooms that do not focus on competition and social comparison (Blumenfeld 1992). In the same vein, Van Yperen and Leander (2014) notably found that even if students pursued mastery goals they relied more on social comparison information (typical of performance-approach goals) rather than temporal comparison information (typical of mastery goals) in order to estimate their competence level. According to these authors, such surprising results can be explained by the fact that the educational system is highly selective, which encourages students to monitor other students' performances (Alon 2009; Harackiewicz et al. 1998). In sum, a consistent body of literature has indicated that students endorse performance-approach goals in the presence of competitive, controlling, and selective environments, such as the University system. Indeed, as we will argue, the University system not only is an institution responsible for knowledge transmission, but it also participates in the process of social mobility within modern Western societies.

\subsection{The functions of university and performance-approach goal endorsement}

According to the functional perspective in sociology of education (Dornbusch et al. 1996), University fulfils two fundamental functions in most Western countries (Darnon et al. 2009, 2012; Dornbusch et al. 1996; Jury et al. 2015; Smeding et al. 2013). First, the educational function, which is the most obvious and the official purpose of any educational system, corresponds to the goal of teaching and increasing students' skills and knowledge. Second, the selection function, which is less explicit although easily observable, corresponds to the goal of rewarding students with different degrees and diplomas based on their academic performance. Even if these two functions are both at the core of the University system, the selection function plays a special role in the functioning of Western societies. Indeed, in industrialized, liberal societies, where important social inequalities exist and in which, paradoxically, equality is such an important value, the educational system has traditionally played the role of "sorting" people based on merit, namely, assigning pupils to "the place where they belong" (Bourdieu et al. 1990; Darnon et al. 2012). In other words, the educational system has the function to identify, through the process of schooling, the best students, that is, those who "deserve" higher degrees (and future higher social status), as well as low achieving students, that is, those who "deserve" lower degrees (and future lower status).

From the perspective of students, this double function implies that if they want to succeed in the system, not only do they have to learn (the official educational function), but they also need to be identified as "good" students relative to others. Thus, the awareness of the selection function of University signals to students that 
performance-approach goals may be useful within the system and therefore represent an important incentive for them to endorse these goals. Consistent with these ideas, research on achievement goal promotion at the University found that students who highly endorse performance-approach goals were judged positively in terms of probability of success within such a system (Darnon et al. 2009).

\subsection{The social value of performance-approach goals}

In order to study achievement goal promotion at the University, Darnon et al. (2009) developed a social value approach to achievement goal endorsement. More precisely, this research examined the extent to which different types of achievement goals are socially valued on the two dimensions of social value: social desirability and social utility (Dubois and Beauvois 2005). Indeed, according to these authors, social value comprises two distinct facets. On the one hand, social desirability refers to the degree of likeableness of a person in his/her relationships with others in a given social environment. On the other hand, social utility refers to one's estimated chances of success within this environment, namely, whether his or her characteristics match the requirements of a given system.

Using this theoretical framework, Darnon et al. (2009) investigated the consequences of achievement goal endorsement on these two facets of social judgment. Their three studies showed that students were particularly ambivalent to performance-approach goals in the University system, since they were associated with low social desirability but high social utility. In other words, participants endorsed performance-approach goals to a higher extent when they were required to demonstrate social utility as opposed to social desirability. Moreover, target students who strongly, as opposed to weakly, endorsed performance-approach goals were judged as less likeable but as having stronger chances to succeed within the system in the eyes of their university teachers (see also Dompnier et al. 2008). Congruently, in the university context, Dompnier et al. (2013) have demonstrated that the more students endorse performance-approach goals for social utility reasons, the more these goals predicted academic performances.

In line with the analysis presented above, Darnon et al. (2009) suggested that the high level of performance-approach goal endorsement under social utility would be the consequence of the fit between these achievement goals and the selection function of the University system. Indeed, endorsing such goals in a system in which being better compared to others is part of how success is defined would be particularly relevant. In other words, reminding students of the selection process that occur at university should motivate them to endorse performance-approach goals, in order to try to make it through this selection process. However, to the best of our knowledge, no direct empirical evidence has so far supported this claim. Such evidence would be necessary to build a model connecting the selective function of University to increased endorsement of performance-approach goals, through the recognition that these goals should be endorsed as a means to succeed (i.e., social utility) within this system. 


\subsection{Overview and hypotheses}

Based on the above review, we hypothesize that when the selection function fulfilled by the University system is made salient, as opposed to when it is not, or to when the educational function is made salient, performance-approach goal endorsement should increase (Hypothesis 1). In the first experiment, the mere activation of selection was tested as a factor that increases performance-approach goal endorsement. The second experiment further tested whether the activation of the selection function of University, as opposed to its educational function, increases performance-approach goal endorsement through increased attribution of social utility to performance-approach goals (Hypothesis 2).

\section{Experiment 1}

\subsection{Method}

\subsubsection{Participants}

Sixty-six students enrolled in the first year of a Master's program in Psychology at a French University voluntarily participated in this experiment (60 women, 6 men, $M_{\text {age }}=22.69, S D=2.05$ ).

\subsubsection{Procedure}

Students participated in this experiment at the beginning of the academic year, during a course. The experiment was presented as a large survey on students' motivation at University, more precisely, as a survey of first year Master's students' motivation. Depending on the experimental condition, participants then read different instructions. In the neutral condition, participants $(n=22)$ read the following instructions:

You have just begun your first year in your Master's program. This year is divided into two semesters. For each semester, the contents will be taught through lectures, workshops, or self-training. Each semester consists of several classes to pass. These units can consist of several topics.

Participants in the selection condition $(n=23)$ read:

You have just begun your first year in your Master's program. Next year, most of you will apply to enter into the second year of the Master's program. As you probably know, there are only a few places. According to the statistics of previous years, only the best among you (about $20 \%$ ) will be admitted in second year.

Indeed, in French Psychology curricula, at the end of the first year in the Master's program, students are heavily selected. First-year Master's students are therefore close to experiencing an important and decisive selection process. In order to ensure 
that merely mentioning the second year of the Master's program (M2) was not in itself sufficient to activate the salience of selection, a third condition was added, which mentioned the second year of the Master's program without reference to the selection process. For participants in this "only Master's 2" condition $(n=21)$, the instruction was as follow:

You have just begun your first year in your Master's program. This year is divided into two semesters. For each semester, the contents will be taught through lectures, workshops, or self-training. Each semester consists of several classes to validate. Passing the first year of the Master's program is a requirement for applying to the second year.

Then participants were asked to report their achievement goals.

\subsubsection{Measures}

Participants completed three performance-approach goal items extracted from Elliot and McGregor's (2001) Achievement Goal Questionnaire (validated in French by Darnon and Butera 2005). Instructions for the questionnaire stated: "The following questions refer to your studies in general. Please indicate the extent to which each statement is true for you in your studies in general." Participants indicated their degree of agreement on a 7-point scale ranging from 1 "Not at all true for me" to 7 "Very true for me" (e.g., "It's important for me to do better than others"; $\alpha=.91$, $M=4.31, S D=1.58$ ). To determine whether the hypothesized effects were specific to performance-approach goals or also applicable to other achievement goals, three mastery-approach goal items (e.g., "I want to learn as much as possible from my classes"; $\alpha=.88, M=5.87, S D=1.01$ ) and the three performanceavoidance goal items (e.g., "I just want to avoid doing poorly in my classes"; $\alpha=.72, M=4.23, S D=1.38$ ) were also included in the experiment. Intercorrelations are presented on Table 1.

\subsection{Results}

Participants were expected to adopt more performance-approach goals when the selection process was made salient than in the two other conditions. Thus, the regression model tested two contrasts: The first contrast compared the selection condition (coded 2) with the neutral and the "only M2" conditions (coded -1 each). The second contrast compared the neutral condition to the "only M2" condition (coded 1 and -1 respectively, with the selection condition coded 0 ).

\subsubsection{Performance-approach goals}

The analyses revealed an effect of the first contrast, $B=.45, S E=.13$, $t(63)=3.58, p<.001, \eta_{p}^{2}=.16,95 \%$ CIs [.20, .70], whereas the second contrast was not significant, $B=-.09, S E=.22, t(63)=-.40, p=.69, \eta_{p}^{2}=.00,95 \%$ CIs $[-.53, .36]$. As illustrated in Fig. 1, participants in the selection condition 
Table 1 Zero-order correlations among variables (Experiment 1)

\begin{tabular}{llll}
\hline Variables & 1 & 2 & 3 \\
\hline 1. Performance-approach goals & - & \\
2. Performance-avoidance goals & $.24^{\mathrm{t}}$ & - & $.28^{*}$ \\
3. Mastery-approach goals & $.27^{*}$ & -.05 & -.08 \\
4. Experimental condition & $-.34^{* *}$ & -.05 & \\
\hline
\end{tabular}

Experimental condition was scored -1 for the selection condition, 0 for the "only M2" condition, and +1 for the neutral condition

${ }^{\mathrm{t}} p<.10 ; * p<.05 ; * * p<.01$

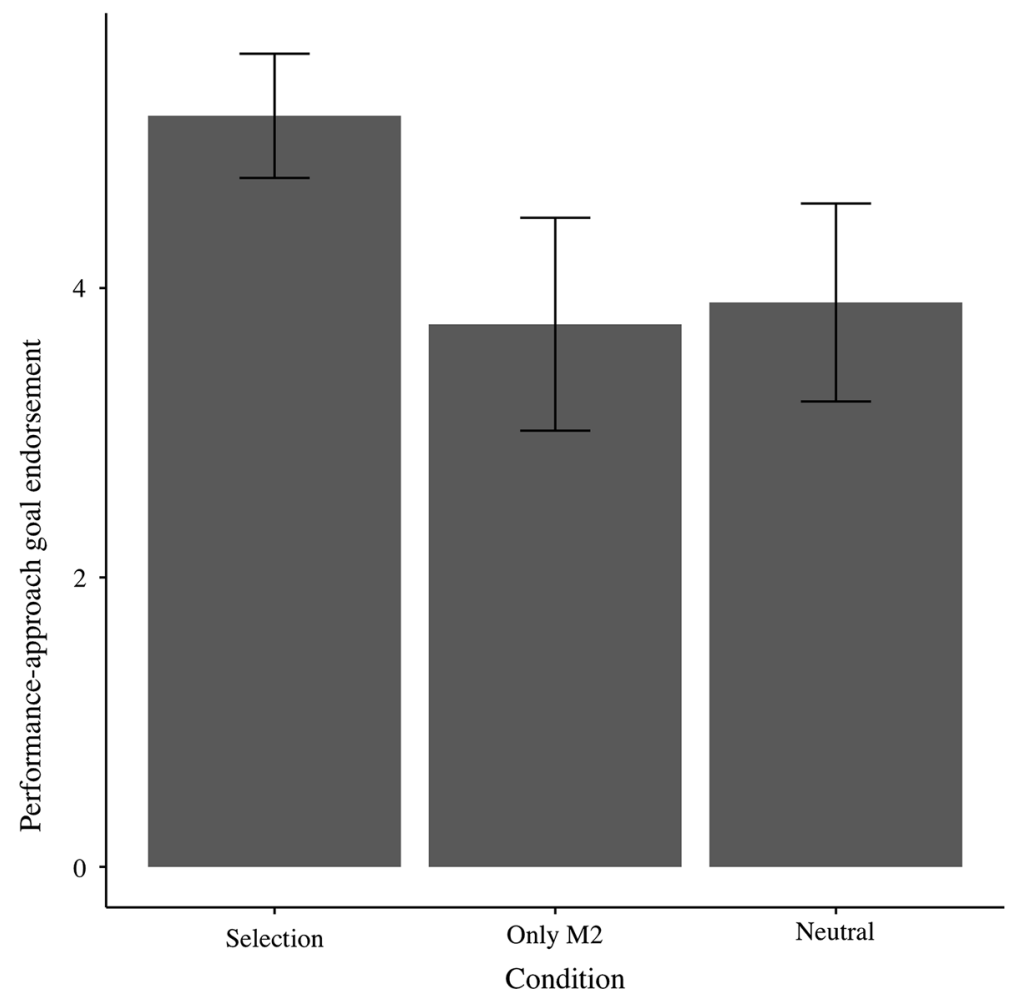

Fig. 1 Mean performance-approach goal endorsement as a function of selection saliency. Errors bars represent standard errors (Experiment 1)

$(M=5.19, S D=1.05)$ reported a higher level of performance-approach goals than did participants in the neutral condition $(M=3.92, S D=1.56)$ and participants in the "only M2" condition $(M=3.75, S D=1.72)$. 


\subsubsection{Other achievement goals}

The same regression model was then tested with mastery-approach and performance-avoidance goals. The results revealed that the contrast of interest was not significant for mastery-approach goal endorsement, $B=.03, S E=.09, t(63)=.30$, $p=.76, \eta_{p}^{2}=.00,95 \%$ CIs $[-.15, .20]$-neither was the orthogonal contrast, $B=.12, S E=.16, t(63)=.78, p=.44, \eta_{p}^{2}=.00,95 \%$ CIs $[-.19, .43]$, or for performance-avoidance goals, $B=.12, S E=.12, t(63)=1.00, p=.32, \eta_{p}^{2}=.01$, $95 \%$ CIs $[-.12, .36]$-neither was the orthogonal contrast, $B=-.21, S E=.21$, $t(63)=-1.00, p=.32, \eta_{p}^{2}=.01,95 \%$ CIs $[-.63, .21]$. Means are presented in Table 2 .

\subsection{Discussion}

The purpose of the first experiment was to examine whether the mere reference to the selection function of the Master's program, would be sufficient to increase students' level of performance-approach goal endorsement. The present results support this hypothesis. Indeed, participants who were reminded, as opposed to not reminded (both with and without reference to the second year of the Master's program), of the selection process they were going to experience, increased their level of performance-approach goal endorsement. The experimental manipulations did not affect other achievement goals (mastery goals and performance-avoidance goals).

Although this result supports Hypothesis 1, it remains unclear at this point what mechanism is responsible for the effect. Our Hypothesis 2 suggests a potential mechanism and proposes that the salience of the selection function makes clear that performance-approach goals are socially useful (Darnon et al. 2009), suggesting that students endorse these goals for the "right reasons" (Dompnier et al. 2009, 2013), namely, because they believe in their utility. If this were the case, performanceapproach goals' social utility should mediate the effect of the selection function on performance-approach goal endorsement. Interestingly, an alternative hypothesis could be that the selection manipulation could also have affected performanceapproach goals' social desirability. Indeed, in a context in which performanceapproach goals are socially undesirable and in which students are aware of the fact

Table 2 Achievement goal endorsement (SD in brackets), Experiment 1

\begin{tabular}{lllll}
\hline $\begin{array}{l}\text { Experimental } \\
\text { condition }\end{array}$ & $n$ & $\begin{array}{l}\text { Performance-approach } \\
\text { goals } \\
M(\mathrm{SD})\end{array}$ & $\begin{array}{l}\text { Mastery-approach } \\
\text { goals } \\
M(\mathrm{SD})\end{array}$ & $\begin{array}{l}\text { Performance-avoidance } \\
\text { goals } \\
M(\mathrm{SD})\end{array}$ \\
\hline $\begin{array}{l}\text { Selection } \\
\text { "Only M2" }\end{array}$ & 23 & $5.19(1.05)$ & $5.93(1.09)$ & $4.46(1.18)$ \\
Neutral & 21 & $3.75(1.72)$ & $5.96(.79)$ & $3.90(1.31)$ \\
\hline
\end{tabular}


that their teachers discourage students to endorse such goals in their class (Darnon et al. 2009; Dompnier et al. 2008), reminding them that selection is going to occur may in some way reduce this undesirability and may have rendered participants more honest in their report of performance-approach goals. In other words, students can reason that if it is socially accepted to talk about selection, it might also be socially accepted to approve of one's endorsement of performance-approach goals. If such an explanation holds true, social desirability of performance-approach goals may (also) mediate the effect of selection on performance-approach goals. In the present experiment, these two explanations will be tested.

\section{Experiment 2}

Experiment 2 tested whether the manipulation of the selection, as opposed to the educational function or a control condition with no mention of University's function, increases performance-approach goal endorsement as well as the perceived social utility of performance-approach goals. The perceived social utility of performance-approach goals is then expected to mediate the effect of the salience of the selection function on performance-approach goal endorsement.

\subsection{Method}

\subsubsection{Participants}

One hundred and thirteen students enrolled in a Psychology Bachelor program at a French University participated in this experiment in exchange for extra course credit. Five participants were excluded from the sample because they did not answer correctly the experimental manipulation check. The final sample included 108 participants (100 women, 8 men) with a mean age of 20.68 years $(S D=4.05)$.

\subsubsection{Procedure}

Participants were welcomed in the laboratory by the experimenter who was blind to the experimental condition. They were seated in front of a computer before receiving some general instructions. The experimental manipulation was introduced at the beginning of the computer program via an introductory text about University's functions.

Participants in the educational $(n=40)$ (vs. selection, $n=33$ ) function conditions read the following introductions:

The first part of our research is qualitative and exploratory. We are interested in Bachelor students' achievement. You probably know that one of the University's functions is to transmit knowledge to students and help them develop skills (vs. identify, among all students, those who will succeed). Thus, in Psychology, for example, the program is conceived in order to help students develop a good understanding of the learning content ( $v s$. identify the best 
students, about $20 \%$ ). We would like to know your opinion as a student concerning this purpose. In your opinion, which type of learning (selection) method should be promoted at the University in order to help students develop their skills (really identify the best students)?

Participants in the control condition $(n=35)$ read the following text:

The first part of our research is qualitative and exploratory. We are interested in Bachelor students' achievement. You probably know that one of the University's functions is to offer the best working conditions to every student. To this effect, in the past two years, our University has been developing a global renovation plan. Last year, the new center for language and multimedia opened. Moreover, the car park was renovated in order to increase green places and offer a better environment. We would like to know you opinion as a student concerning this purpose. In your opinion, which areas would need to be renovated next to offer better workings conditions to students?

The final question in each condition aimed to reinforce the instructions, and required participants to write a short text. This question also served to identify those who did not understand the instructions (cf. participants' section). ${ }^{2}$ After completing this first task, participants had to complete the performance-approach goal and the social value questionnaires. Participants were then fully debriefed. In particular, they were informed that the selection rate presented in the selection condition did not represent the reality.

\subsubsection{Measures}

Achievement goals Participants completed the Elliot and McGregor's (2001) questionnaire, the same as in the first experiment. Reliability analyses and intercorrelations are presented in Table 3.

Achievement goals' social utility and social desirability In order to assess achievement goals' social utility and social desirability, participants were asked to complete again the scale but with two different self-presentation instructions (see Dompnier et al. 2009, 2013). The social utility instruction was as follows:

Imagine that your teachers ask the same questions and that you should convince them that you are a smart student. Try to endorse this role and answer these questions again. In other words, we would like you to try to show you are a student who possesses all the qualities to succeed at university, in the eyes of others and notably your teachers.

\footnotetext{
${ }^{2}$ Participants reported various types of answers (e.g., "Continuous assessment seems to be the best solution because it requires daily work"; "internships should be favored to help students developing their skills"). Two independent judges with the instruction of identifying if participants properly answer the manipulation check question rated each answer. Those not related to the question were considered as unsatisfactory. Agreement between the two judges was moderate $(k=.56)$. Judges both agreed that five participants did not answer the question properly. These participants were removed from the final sample.
} 
Table 3 Zero-order correlations among variables (Experiment 2)

\begin{tabular}{|c|c|c|c|c|c|c|c|c|c|c|}
\hline Variables & $\alpha$ & 1 & 2 & 3 & 4 & 5 & 6 & 7 & 8 & 9 \\
\hline $\begin{array}{l}\text { 1. Performance-approach } \\
\text { goals }\end{array}$ & .82 & - & & & & & & & & \\
\hline $\begin{array}{l}\text { 2. Performance-approach } \\
\text { social utility }\end{array}$ & .92 & $.35 * *$ & - & & & & & & & \\
\hline $\begin{array}{l}\text { 3. Performance-approach } \\
\text { social desirability }\end{array}$ & .91 & $.42 * *$ & $.43 * *$ & - & & & & & & \\
\hline 4. Mastery-approach goals & .85 & $.29 * *$ & $.31 * *$ & .15 & - & & & & & \\
\hline $\begin{array}{l}\text { 5. Mastery-approach social } \\
\text { utility }\end{array}$ & .95 & .03 & $.56^{* *}$ & .13 & $.31 * *$ & - & & & & \\
\hline $\begin{array}{l}\text { 6. Mastery-approach social } \\
\text { desirability }\end{array}$ & .93 & .06 & $.40 * *$ & $.33 * *$ & $.39 * *$ & $.56^{* *}$ & - & & & \\
\hline $\begin{array}{l}\text { 7. Performance-avoidance } \\
\text { goals }\end{array}$ & .80 & $.45 * *$ & .13 & $.21 *$ & $.20 *$ & -.03 & .01 & - & & \\
\hline $\begin{array}{l}\text { 8. Performance-avoidance } \\
\text { social utility }\end{array}$ & .83 & .02 & $.27 * *$ & -.06 & .04 & $.20 *$ & .01 & $.21 *$ & - & \\
\hline $\begin{array}{l}\text { 9. Performance-avoidance } \\
\text { social desirability }\end{array}$ & .71 & $.24^{*}$ & $.29 * *$ & $.23 *$ & $.31 * *$ & .15 & $.31 * *$ & $.38 * *$ & $.54 * *$ & - \\
\hline 10. Experimental condition & - & $.25^{*}$ & .13 & .03 & .04 & .02 & .07 & $.18^{\mathrm{t}}$ & .03 & $.18^{\mathrm{t}}$ \\
\hline
\end{tabular}

Experimental condition was scored -1 for the control condition, 0 for the educational function condition, and +1 for the selection function condition

${ }^{\mathrm{t}} p<.10 ; * p<.05 ; * * p<.01$

The social desirability instruction was as follows:

Imagine that your teachers ask the same questions and that you should convince them that you are a pleasant student. Try to endorse this role and answer these questions again. In other words, we would like you to try to show you are a student who possesses all the qualities to be appreciated by others and notably by your teachers.

Participants always answered the standard instructions first in order to obtain an uncontaminated measure of their spontaneous goal endorsement. Then they answered the social desirability and social utility instructions, which were counterbalanced across participants.

\subsection{Results}

As in Experiment 1, the regression model integrated two contrasts. Participants in the selection condition were expected to report a higher level of performanceapproach goals compared to participants in other two conditions. Thus, the first contrast compared the selection function condition (coded 2) with the educational function and the control conditions (coded -1 each). The second contrast compared the educational condition (1) with the control condition $(-1$, with the selection condition coded 0 ). 


\subsubsection{Performance-approach goals}

The analyses revealed a significant effect of the first contrast, $B=.24, S E=.09$, $t(105)=2.69, p=.008, \eta_{p}^{2}=.06,95 \%$ CIs $[.06, .41]$, whereas the second was not significant $\left(B=.09, S E=.15, t(105)=.62, p=.54, \eta_{p}^{2}=.00,95 \%\right.$ CIs [-.20, .38]). As shown on Fig. 2, participants in the selection function condition $(M=3.61, S D=1.30)$ were more likely to endorse performance-approach goals than participants in the educational function condition $(M=2.98, S D=1.15)$ and the control condition $(M=2.80, S D=1.37)$.

\subsubsection{Performance-approach goals' social utility}

The same regression analysis was repeated on performance-approach goals' social utility. A significant effect of the first contrast, $B=.23, S E=.11, t(105)=2.07$, $p=.041, \eta_{p}^{2}=.03,95 \%$ CIs [.01, .44], indicated that participants in the selection function condition $(M=5.74, S D=1.24)$ reported a higher social utility of performance-approach goals compared to participants in the educational function condition $(M=4.90, S D=1.73)$ and the control condition $(M=5.21$, $S D=1.67)$. The second contrast was not significant $(B=-.15, S E=.18$, $t(105)=-.85, p=.40, \eta_{p}^{2}=.00,95 \%$ CIs $\left.[-.52, .21]\right)$.

\subsubsection{Performance-approach goals' social desirability}

The same regression analysis was then conducted on performance-approach goals' social desirability. Neither the first contrast, $B=.06, S E=.11, t(105)=.56$, $p=.58, \eta_{p}^{2}=.00,95 \%$ CIs $[-.15, .27]$, nor the second contrast $[B=-.05$, $S E=.18, \quad t(105)=-.29, \quad p=.77, \quad \eta_{p}^{2}=.00,95 \%$ CIs $\left.(-.41, .30)\right]$ were significant.

\subsubsection{Mediation analysis}

Since the effect of the contrast on social desirability of performance-approach goals was not obtained, social desirability could not be tested as a potential mediator. Thus, the meditational analysis only tested social utility as a mediator of the effect of the contrast on performance-approach goal endorsement. As illustrated on Fig. 3, this analysis showed a significant reduction in the total effect of our contrast on performance-approach goal endorsement. If the direct effect remained significant, $B=.18, S E=.09, t(104)=2.09, p=.039, \eta_{p}^{2}=.04,95 \%$ CIs $[.01, .35]$, the indirect effect through performance-approach goals' social utility would also be significant. Indeed, across 10,000 trials, the bootstrap estimated indirect effect was $.05,95 \%$ CIs $[.01, .13]$, an effect that can be considered as small, $a b_{c s}=.06,95 \%$ CIs $[.01, .13]$ (Preacher and Hayes 2008). ${ }^{3}$

\footnotetext{
${ }^{3}$ It should be noted that a fourth condition $(n=35)$ was initially included in this experiment. This condition promoted a mixed discourse about the selection and the educational functions. As this condition
} 


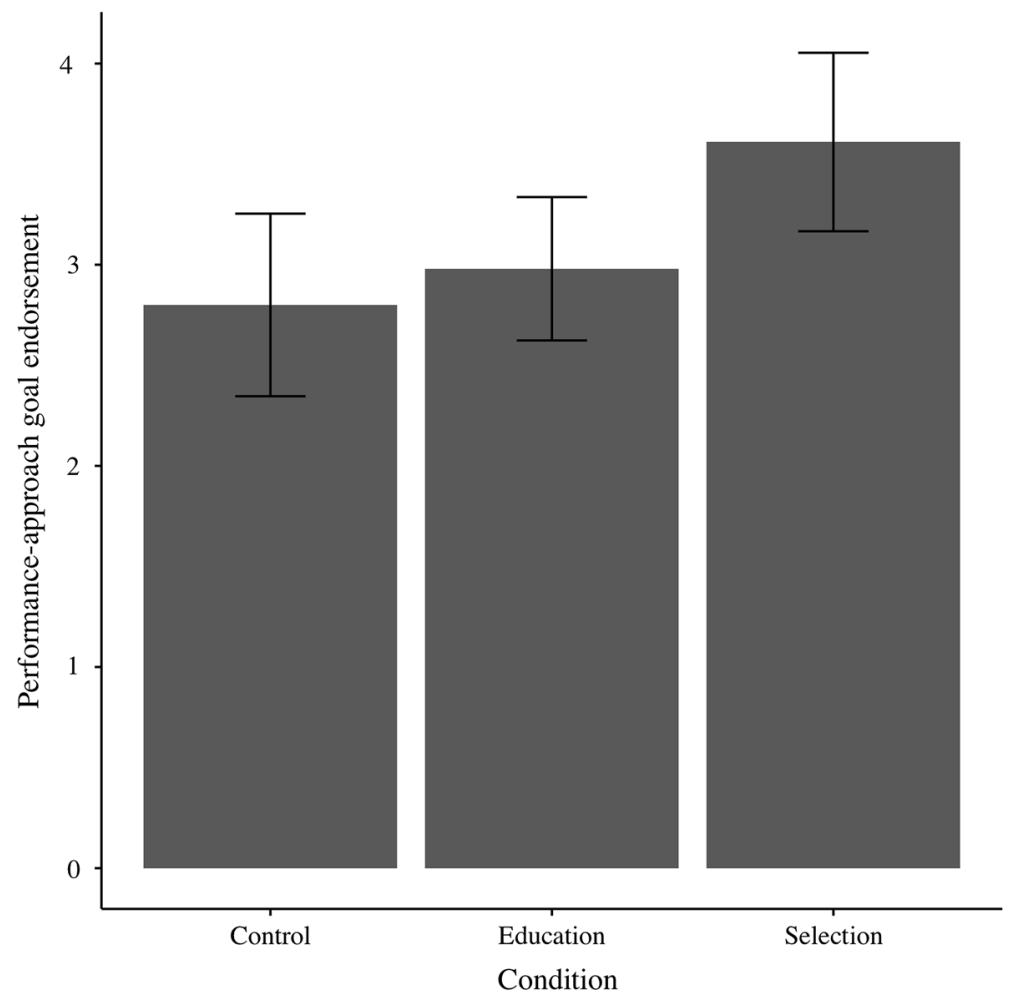

Fig. 2 Mean performance-approach goal endorsement as a function of selection saliency. Errors bars represent standard errors (Experiment 2)

\subsubsection{Other achievement goals}

The same regression models were tested on mastery-approach and performanceavoidance goals. For mastery-approach goals, the contrast of interest was significant neither for their adoption, $B=.10, S E=.13, t(105)=.76, p=.46, \eta_{p}^{2}=.00$ $95 \%$ CIs $[-.16, .35]$, nor their social utility, $B=.01, S E=.11, t(105)=.11$,

Footnote 3 continued

was ambiguous, for clarity reasons, it was not presented here. Nevertheless, it should be noted that testing a contrast between the selection condition (coded 3) and the three others conditions (coded -1 each) produced the same results: The selection condition elicited higher performance-approach goal endorsement compared to the three other conditions, $B=.18, S E=.06, t(139)=2.98, p=.003, \eta_{p}^{2}=.06$, $95 \%$ CIs $[.06, .30]$, as well as higher social utility associated to these goals, $B=0.15, S E=0.08$, $t(139)=2.00, p=.047, \eta_{p}^{2}=.02,95 \%$ CIs $[.00, .30]$, and did not reduce the social undesirability associated with these goals, $B=0.05, S E=0.08, t(139)=0.65, p=.52, \eta_{p}^{2}=.00,95 \%$ CIs [-.10, .20]. Entering social utility in the regression model with the contrast produced a significant reduction in the coefficient of the contrast effect, which remained significant, $B=0.14, S E=0.06, t(138)=2.45$, $p=.015, \eta_{p}^{2}=.04,95 \%$ CIs $[.03, .26]$. This indirect effect was $0.03,95 \%$ CIs [.00, .08], a small effect, $a b_{c s}=04,95 \%$ CIs $[.00, .10]$. No results were significant for mastery approach-goals and performanceavoidance goals. Full results are available on request. 


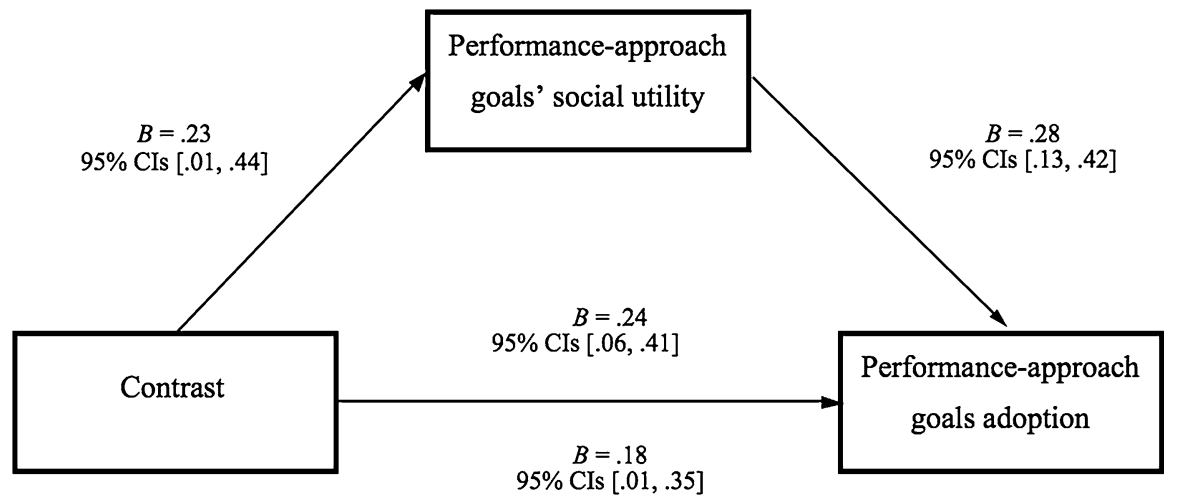

Fig. 3 Mediation of the contrast of interest (selection condition vs. educational and control condition) on performance-approach goal adoption by performance-approach goals social utility (Experiment 2). $* p<.05 ; * * p<.01 ; * * * p<.001$

$p=.91, \eta_{p}^{2}=.00,95 \%$ CIs $[-.21, .23]$, nor their social desirability, $B=.07$, $S E=.14, t(105)=.48, p=.63, \eta_{p}^{2}=.00,95 \%$ CIs $[-.21, .34]$. The orthogonal contrast did not reach significance either (adoption: $B=-.06, \quad S E=.14$, $t(105)=-.40, p=.69, \eta_{p}^{2}=.00,95 \%$ CIs $[-.34, .23]$; social utility, $B=.02$, $S E=.12, t(105)=.18, p=.86, \eta_{p}^{2}=.00,95 \%$ CIs $[-.22, .26]$; social desirability; $B=.09, S E=.15, t(105)=.59, p=.56, \eta_{p}^{2}=.00,95 \%$ CIs $\left.[-.21, .39]\right)$.

As far as performance-avoidance goals are concerned, the contrast of interest was neither significant for their adoption, $B=.18, S E=.13, t(105)=1.37, p=.17$, $\eta_{p}^{2}=.01,95 \%$ CIs $[-.08, .44]$, nor their social utility, $B=.13, S E=.19$, $t(105)=.65, p=.52, \eta_{p}^{2}=.00,95 \%$ CIs $[-.25, .50]$, nor their social desirability, $B=.25, S E=.15, t(105)=1.69, p=.094, \eta_{p}^{2}=.02,95 \%$ CIs $[-.04, .55]$. The orthogonal contrast did not reach significance either (adoption: $B=.22, S E=.15$, $t(105)=1.53, p=.13, \eta_{p}^{2}=.02,95 \%$ CIs $[-.07, .51]$; social utility, $B=-.10$, $S E=.21, t(105)=-.47, p=.64, \eta_{p}^{2}=.00,95 \%$ CIs $[-.52, .32] ;$ social desirability; $B=.14, \quad S E=.17, t(105)=.83, p=.41, \quad \eta_{p}^{2}=.00,95 \%$ CIs $[-.19, .47])$. Means are presented in Table 4.

\subsection{Discussion}

First, this experiment replicated the effect of the salience of the selection function on performance-approach goal endorsement (first contrast). In addition, activating the educational function of the system did not change performance-approach goal endorsement level (second contrast). Thus, in line with Hypothesis 1, and consistent with Experiment 1, when the selection function of the educational system was made salient, students' endorsement of performance-approach goals increased. Moreover, in line with Hypothesis 2, the results of the present experiment indicated that social utility of performance-approach goals has an indirect effect on performance- 


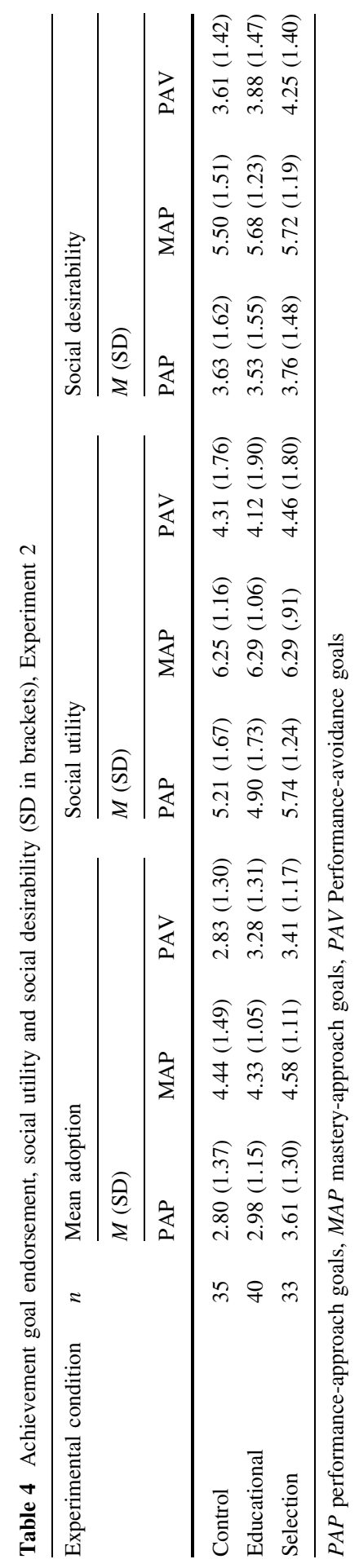


approach goal endorsement, whereas social desirability has not. Thus, the interpretation of the effect of selection on performance-approach goals in term of social desirability is not supported by the present data. Rather, the present result tends to support the hypothesis, according to which the selection function that the educational system fulfills in society provides value to performance-approach goals in terms of social utility. This increase in social utility further explains why students who face selection are particularly prone to endorse such goals, namely, because they believe in their efficacy to succeed (Dompnier et al. 2013).

\section{General discussion}

The present article argued that in addition to its obvious and official educational function, the University system also fulfills a selection function (Darnon et al. 2009; Dornbusch et al. 1996), which motivates students to endorse performance-approach goals. The results of two experiments support to this hypothesis. Indeed, both Experiments 1 and 2 documented that when the selection function of the system was made salient, an increase in performance-approach goal endorsement was observed. Moreover, it was argued that this increase in performance-approach goal endorsement was partly due to the social utility value attached to performanceapproach goals. In particular, Hypothesis 2 proposed a structural explanation of the effect of the selection function, such that the increase in performance-approach goal endorsement would be due to the very role that the educational system plays in the society. Because the selection process is part of the functioning of the system, and in particular, its important function in society (i.e., to "sort" students and distribute unequal positions, Dubet and Duru-Bellat 2004; Duru-Bellat 1996), performanceapproach goals should be particularly valued in terms of social utility (Darnon et al. 2009; Dubois and Beauvois 2005). The results tend to confirm this hypothesis by showing that social utility of performance-approach goals contribute to explaining the effect of selection saliency on performance-approach goal adoption. Therefore, results tend to support the structural explanation of the effects, and more generally, the idea that the selection function leads students to endorse performance-approach goals because this function convinces them of these goals' social utility. Interestingly, promoting the educational function of the system did not raise performance-approach goal endorsement, showing that the system, per se, does not automatically increase students' focus on normative difference with others. However, it did not decrease their focus either. Thus, promoting education, which is the main and most obvious function of the educational system, does not seem to be sufficient for reducing performance-approach goal social value and endorsement.

The present research proposed and tested an additional explanation of the effect of selection on performance-approach goals. As performance-approach goals are undesirable (Darnon et al. 2009; Dompnier et al. 2008), the selection induction may increase the desirability of these goals, which might explain why students report these goals more frequently after the induction. The present results did not support this hypothesis, as social desirability of performance-approach goals was not affected when the selection function was promoted. However, more research is 
needed to refine our understanding of the mechanisms involved in the current findings. Moreover, a limitation of the present studies is the gender composition of the sample. In our patriarchal societies, men and women differ on how they experience competition (Niederle and Vesterlund 2008; for the situation in matrilineal societies see Gneezy et al. 2009), and being competitive is notably less desirable for women than for men (Prentice and Carranza 2002). Thus, in the present experiment, conducted mainly on women, the salience of the selection induction might not sufficiently reduce, in women's eyes, the social undesirability of performance-approach goals. Testing whether the social utility and social desirability associated with performance-approach goals mediate the effect of selection on performance-approach goal endorsement on a more balanced sample would clarify this issue. In addition, mediators are measured after the dependent variable (i.e., to avoid obtaining a contaminated measure of their spontaneous goal endorsement) and are very close to this one (i.e., same scale with a different instruction). A replication of these results with another way of assessing performance-approach goals social value that also respect temporal precedence rule is needed.

Taken together, these two experiments provide empirical support of the idea that the University system encourages students to endorse performance-approach goals. This selection function should then be considered when trying to understand why, in spite of teachers' sincere intention not to promote performance-approach goals in their classrooms, these goals continue to be endorsed by students (see Blumenfeld 1992; Darnon et al. 2009; Van Yperen and Leander 2014). It could also explain why performance-approach goals remain constant or rise during College while masteryapproach, mastery-avoidance, and performance-avoidance goals decline (Corker et al. 2013; Lieberman and Remedios 2007; Stewart et al. 2015).

More generally speaking, the present experiments confirmed that in addition to the role of individual and contextual antecedents of goals endorsement, the role of the larger system should not be ignored (Darnon et al. 2012). Indeed, in addition to other factors including classroom climate (Meece et al. 2006), evaluation practices (Pekrun et al. 2014), or teacher's practices (Nichols et al. 2003; Urdan and Schoenfelder 2006), these results tend to confirm that the educational system and the role this system plays in the society also influence the extent to which students endorse these goals in the classroom. Moreover, the results also document that social value, in the present case social utility value, contributes to explaining why some contexts favor performance-approach goals.

Although recent research underlies some positive consequences of endorsing performance-approach goals (Chen 2015; for a meta-analysis on performances, see Van Yperen et al. 2014), teachers and researchers still need to consider several negative outcomes associated with performance-approach goals (Crouzevialle and Butera 2013; Grant and Dweck 2003; Harackiewicz et al. 2000; Kaplan and Maehr 1999). For example, performance-approach goals appear to be particularly problematic for relational outcomes by reducing the quality of information exchanges (Poortvliet et al. 2007), help-seeking and help-giving (Butler and Neuman 1995; Poortvliet and Darnon 2014), favoring poor forms of conflict regulation (Darnon et al. 2007a, b; Sommet et al. 2014) and valuating cooperation 
for social status purpose (Levy et al. 2004). Therefore, the selection function, as it results in performance-approach goal promotion, may be problematic in an educational system where students are supposed to be taught not only academic content, but also peaceful and cooperative attitudes toward others.

Acknowledgments This research was supported by the French Agence Nationale de la Recherche (ANR 11 INEG 002 02), the Swiss National Science Foundation (SINERGIA), and the Région Auvergne.

\section{Compliance with ethical standards}

Conflict of interest The authors declare that they have no conflict of interest.

\section{References}

Alon, S. (2009). The evolution of class inequality in higher education: Competition, exclusion, and adaptation. American Sociological Review, 74(5), 731-755. doi:10.1177/000312240907400503.

Ames, C. (1992). Classrooms: Goals, structures, and student motivation. Journal of Educational Psychology, 84(3), 261-271. doi:10.1037/0022-0663.84.3.261.

Berger, N., \& Archer, J. (2016). School socio-economic status and student socio-academic achievement goals in upper secondary contexts. Social Psychology of Education, 19(1), 175-194. doi:10.1007/ s11218-015-9324-8.

Blumenfeld, P. C. (1992). Classroom learning and motivation: Clarifying and expanding goal theory. Journal of Educational Psychology, 84(3), 272-281. doi:10.1037//0022-0663.84.3.272.

Bourdieu, P., Passeron, J.-C., \& Nice, R. (1990). Reproduction in education, society and culture (2nd ed.). Thousand Oaks, CA: Sage.

Brophy, J. (2005). Goal theorists should move on from performance goals. Educational Psychologist, 40(3), 167-176. doi:10.1207/s15326985ep4003_3.

Butler, R., \& Neuman, O. (1995). Effects of task and ego achievement goals on help-seeking behaviors and attitudes. Journal of Educational Psychology, 87(2), 261-271. doi:10.1037/0022-0663.87.2.261.

Chen, C. (2015). Incremental validity of achievement goals in predicting subjective well-being among university students. Journal of Cognitive Education and Psychology, 14(1), 38-62. doi:10.1891/ 1945-8959.14.1.38.

Corker, K. S., Donnellan, M. B., \& Bowles, R. P. (2013). The development of achievement goals throughout college: Modeling stability and change. Personality and Social Psychology Bulletin, 39(11), 1404-1417. doi:10.1177/0146167213494243.

Crouzevialle, M., \& Butera, F. (2013). Performance-approach goals deplete working memory and impair cognitive performance. Journal of Experimental Psychology: General, 142(3), 666-678. doi:10. 1037/a0029632.

Cury, F., Elliot, A. J., Da Fonseca, D., \& Moller, A. C. (2006). The social-cognitive model of achievement motivation and the $2 \times 2$ achievement goal framework. Journal of Personality and Social Psychology, 90(4), 666-679. doi:10.1037/0022-3514.90.4.666.

Darnon, C., \& Butera, F. (2005). Buts d'accomplissement, stratégies d'étude, et motivation intrinsèque : présentation d'un domaine de recherche et validation française de l'échelle d'Elliot et McGregor (2001) [Achievement goals, study strategies, and intrinsic motivation: Presenting a domain of research and the French validation of Elliot and McGregor's (2001) scale]. L'année Psychologique, 105(1), 105-131. doi:10.3406/psy.2005.3821.

Darnon, C., Butera, F., \& Harackiewicz, J. M. (2007a). Achievement goals in social interactions: Learning with mastery vs. performance goals. Motivation and Emotion, 31(1), 61-70. doi:10.1007/ s11031-006-9049-2.

Darnon, C., Dompnier, B., Delmas, F., Pulfrey, C., \& Butera, F. (2009). Achievement goal promotion at university: Social desirability and social utility of mastery and performance goals. Journal of Personality and Social Psychology, 96(1), 119-134. doi:10.1037/a0012824. 
Darnon, C., Dompnier, B., \& Poortvliet, M. (2012). Achievement goals in educational contexts: A social psychology perspective. Social and Personality Psychology Compass, 6(10), 760-771. doi:10.1111/ j.1751-9004.2012.00457.x.

Darnon, C., Harackiewicz, J. M., Butera, F., Mugny, G., \& Quiamzade, A. (2007b). Performanceapproach and performance avoidance goals: When uncertainty makes a difference. Personality and Social Psychology Bulletin, 33(6), 813-827. doi:10.1177/0146167207301022.

Dompnier, B., Darnon, C., \& Butera, F. (2009). Faking the desire to learn: A clarification of the link between mastery goals and academic achievement. Psychological Science, 20(8), 939-943. doi:10. 1111/j.1467-9280.2009.02384.x.

Dompnier, B., Darnon, C., \& Butera, F. (2013). When performance-approach goals predict academic achievement and when they do not: A social value approach. British Journal of Social Psychology, 52(3), 587-596. doi:10.1111/bjso.12025.

Dompnier, B., Darnon, C., Delmas, F., \& Butera, F. (2008). Achievement goals and social judgment: The performance-approach goals paradox. Revue Internationale de Psychologie Sociale, 21(1), 247-271.

Dornbusch, S. M., Glasgow, K. L., \& Lin, I.-C. (1996). The social structure of schooling. Annual Review of Psychology, 47, 401-429. doi:10.1146/annurev.psych.47.1.401.

Dubet, F., \& Duru-Bellat, M. (2004). Qu'est-ce qu'une école juste ? [What is a fair school?]. Revue Française de Pédagogie, 146(1), 105-114. doi:10.3406/rfp.2004.3099.

Dubois, N., \& Beauvois, J.-L. (2005). Normativeness and individualism. European Journal of Social Psychology, 35, 123-146. doi:10.1002/ejsp.236.

Duru-Bellat, M. (1996). Social inequalities in French secondary schools: From figures to theories. British Journal of Sociology of Education, 17(3), 341-350. doi:10.1080/0142569960170307.

Elliot, A. J. (2005). A conceptual history of the achievement goal construct. In A. J. Elliot \& C. S. Dweck (Eds.), Handbook of competence and motivation (pp. 52-72). New York, NY: Guilford Press.

Elliot, A. J., \& McGregor, H. A. (2001). A $2 \times 2$ achievement goal framework. Journal of Personality and Social Psychology, 80(3), 501-519. doi:10.1037/0022-3514.80.3.501.

Elliot, A. J., Murayama, K., \& Pekrun, R. (2011). A $3 \times 2$ achievement goal model. Journal of Educational Psychology, 103(3), 632-648. doi:10.1037/a0023952.

Gneezy, U., Leonard, K. L., \& List, J. A. (2009). Gender differences in competition: Evidence from a matrilineal and a patriarchal society. Econometrica, 77(5), 1637-1664.

Grant, H., \& Dweck, C. S. (2003). Clarifying achievement goals and their impact. Journal of Personality and Social Psychology, 85(3), 541-553. doi:10.1037/0022-3514.85.3.541.

Harackiewicz, J., Barron, K., \& Elliot, A. (1998). Rethinking achievement goals: When are they adaptive for college students and why? Educational Psychologist, 33(1), 1-21. doi:10.1207/ s15326985ep3301_1.

Harackiewicz, J. M., Barron, K. E., Pintrich, P. R., Elliot, A. J., \& Thrash, T. M. (2002). Revision of achievement goal theory: Necessary and illuminating. Journal of Educational Psychology, 94(3), 638-645. doi:10.1037/0022-0663.94.3.638.

Harackiewicz, J. M., Barron, K. E., Tauer, J. M., Carter, S. M., \& Elliot, A. J. (2000). Short-term and long-term consequences of achievement goals: Predicting interest and performance over time. Journal of Educational Psychology, 92(2), 316-330. doi:10.1037/0022-0663.92.2.316.

Jury, M., Smeding, A., \& Darnon, C. (2015). First-generation students' underperformance at university: The impact of the function of selection. Frontiers in Psychology, 6, 710. doi:10.3389/fpsyg.2015. 00710.

Kaplan, A., \& Maehr, M. L. (1999). Achievement goals and student well-being. Contemporary Educational Psychology, 24(4), 330-358. doi:10.1006/ceps.1999.0993.

Kaplan, A., \& Middleton, M. J. (2002). Should childhood be a journey or a race? Response to Harackiewicz et al. (2002). Journal of Educational Psychology, 94(3), 646-648. doi:10.1037/00220663.94.3.646.

Levy, I., Kaplan, A., \& Patrick, H. (2004). Early adolescents' achievement goals, social status, and attitudes towards cooperation with peers. Social Psychology of Education, 7(2), 127-159. doi:10. 1023/B:SPOE.0000018547.08294.b6.

Lieberman, D. A., \& Remedios, R. (2007). Do undergraduates' motives for studying change as they progress through their degrees? British Journal of Educational Psychology, 77(2), 379-395. doi:10. 1348/000709906X157772.

Maehr, M., \& Midgley, C. (1991). Enhancing student motivation: A schoolwide approach. Educational Psychologist, 26(3), 399-427. doi:10.1207/s15326985ep2603\&4_9. 
Meece, J. L., Anderman, E. M., \& Anderman, L. H. (2006). Classroom goal structure, student motivation, and academic achievement. Annual Review of Psychology, 57, 487-503. doi:10.1146/annurev.psych. 56.091103 .070258 .

Moller, A. C., \& Elliot, A. J. (2006). The $2 \times 2$ achievement goal framework: An overview of empirical research. In A. V. Mittel (Ed.), Focus on educational psychology (pp. 307-326). Hauppauge, NY: Nova Science Publishers.

Murayama, K., \& Elliot, A. J. (2012). The competition-performance relation: A meta-analytic review and test of the opposing processes model of competition and performance. Psychological Bulletin, 138(6), 1035-1070. doi:10.1037/a0028324.

Nicholls, J. G. (1989). The competitive ethos and democratic education. Cambridge, MA: Harvard University Press.

Nichols, W. D., Jones, J. P., \& Hancock, D. R. (2003). Teachers' influence on goal orientation: Exploring the relationship between eighth graders' goal orientation, their emotional development, their perceptions of learning, and their teachers' instructional strategies. Reading Psychology, 24(1), 57-85. doi:10.1080/02702710308236.

Niederle, M., \& Vesterlund, L. (2008). Gender differences in competition. Negotiation Journal, 24(4), 447-463. doi:10.1111/j.1571-9979.2008.00197.x.

Pekrun, R., Cusack, A., Murayama, K., Elliot, A. J., \& Thomas, K. (2014). The power of anticipated feedback: Effects on students' achievement goals and achievement emotions. Learning and Instruction, 29, 115-124. doi:10.1016/j.learninstruc.2013.09.002.

Poortvliet, P. M., \& Darnon, C. (2014). Understanding positive attitudes toward helping peers: The role of mastery goals and academic self-efficacy. Self and Identity, 13(3), 345-363. doi:10.1080/15298868. 2013.832363 .

Poortvliet, M., Janssen, O., Van Yperen, N. W., \& Van de Vliert, E. (2007). Achievement goals and interpersonal behavior: How mastery and performance goals shape information exchange. Personality and Social Psychology Bulletin, 33(10), 1435-1447. doi:10.1177/0146167207305536.

Pope, D. C. (2001). Doing school: How we are creating a generation of stressed out, materialistic, and miseducated students. New Haven, CT: Yale University Press.

Preacher, K. J., \& Hayes, A. F. (2008). Contemporary approaches to assessing mediation in communication research. In A. F. Hayes, M. D. Slater, \& L. B. Snyder (Eds.), The Sage sourcebook of advanced data analysis methods for communication research (pp. 13-54). Thousand Oaks, CA: Sage.

Prentice, D. A., \& Carranza, E. (2002). What women and men should be, shouldn't be, are allowed to be, and don't have to be: The contents of prescriptive gender stereotypes. Psychology of Women Quarterly, 26(4), 269-281. doi:10.1111/1471-6402.t01-1-00066.

Senko, C., Hulleman, C. S., \& Harackiewicz, J. M. (2011). Achievement goal theory at the crossroads: Old controversies, current challenges, and new directions. Educational Psychologist, 46(1), $26-47$. doi:10.1080/00461520.2011.538646.

Skaalvik, E. M., \& Federici, R. A. (2016). Relations between classroom goal structures and students' goal orientations in mathematics classes: When is a mastery goal structure adaptive? Social Psychology of Education, 19(1), 135-150. doi:10.1007/s11218-015-9323-9.

Skaalvik, E. M., \& Skaalvik, S. (2013). School goal structure: Associations with students' perceptions of their teachers as emotionally supportive, academic self-concept, intrinsic motivation, effort, and help seeking behavior. International Journal of Educational Research, 61, 5-14. doi:10.1016/j.ijer. 2013.03.007.

Smeding, A., Darnon, C., Souchal, C., Toczek-Capelle, M.-C., \& Butera, F. (2013). Reducing the socioeconomic status achievement gap at University by promoting mastery-oriented assessment. PLoS One, 8(8), e71678. doi:10.1371/journal.pone.0071678.

Sommet, N., Darnon, C., Mugny, G., Quiamzade, A., Pulfrey, C., Dompnier, B., et al. (2014). Performance goals in conflictual social interactions: Towards the distinction between two modes of relational conflict regulation. British Journal of Social Psychology, 53(1), 134-153. doi:10.1111/ bjso. 12015 .

Stewart, M., Stott, T., \& Nuttall, A.-M. (2015). Study goals and procrastination tendencies at different stages of the undergraduate degree. Studies in Higher Education,. doi:10.1080/03075079.2015. 1005590 .

Urdan, T., \& Schoenfelder, E. (2006). Classroom effects on student motivation: Goal structures, social relationships, and competence beliefs. Journal of School Psychology, 44(5), 331-349. doi:10.1016/j. jsp.2006.04.003. 
Van Yperen, N. W., Blaga, M., \& Postmes, T. (2014). A meta-analysis of self-reported achievement goals and nonself-report performance across three achievement domains (work, sports, and education). PLoS One, 9(4), e93594. doi:10.1371/journal.pone.0093594.

Van Yperen, N. W., \& Leander, N. P. (2014). The overpowering effect of social comparison information: On the misalignment between mastery-based goals and self-evaluation criteria. Personality and Social Psychology Bulletin, 40(5), 676-688. doi:10.1177/0146167214523475.

Wang, M.-T., \& Degol, J. L. (2015). School climate: A review of the construct, measurement, and impact on student outcomes. Educational Psychology Review,. doi:10.1007/s10648-015-9319-1.

Mickaël Jury received his Ph.D. in social psychology from Université Clermont Auvergne, France. He is now a post-doc fellow at the University of Geneva, Switzerland. His research interests are in the area of achievement motivation with a main focus on the antecedents of achievement goals in the university context.

Céline Darnon is an assistant professor at Université Clermont Auvergne, France. She examines how the values promoted within the educational system impact students' motivation, goals and achievement and how it can contribute to the social reproduction of inequalities between boys and girls, high and low social class students.

Benoît Dompnier is a senior lecturer in social psychology at University of Lausanne, Switzerland. His research interests focus on achievement motivation, social judgment and self-presentation strategies in educational contexts.

Fabrizio Butera is Professor of Social Psychology at the University of Lausanne, Switzerland, as well as Director of the Social Psychology Laboratory. His research interests focus on social influence processes, conflict, and social comparison. He is currently funded by the Swiss National Science Foundation, under the form of a Sinergia grant to study the social psychological influences intervening in academic selection. 